Research Article

\title{
Hemodynamic Characteristics of Mechanically Ventilated COVID-19 Patients: A Cohort Analysis
}

\author{
E. Christiaan Boerma ${ }^{D}$, Carina Bethlehem, Franciena Stellingwerf, Fellery de Lange, \\ Koen W. Streng, Peter M. Koetsier, and Inge T. Bootsma
}

Department of Intensive Care, Medical Centre Leeuwarden, Leeuwarden, Netherlands

Correspondence should be addressed to E. Christiaan Boerma; boermachristiaan@gmail.com

Received 18 August 2020; Revised 30 November 2020; Accepted 18 December 2020; Published 5 January 2021

Academic Editor: Quincy K Tran

Copyright $\odot 2021$ E. Christiaan Boerma et al. This is an open access article distributed under the Creative Commons Attribution License, which permits unrestricted use, distribution, and reproduction in any medium, provided the original work is properly cited.

\begin{abstract}
Background. Solid data on cardiovascular derangements in critically ill COVID-19 patients remain scarce. The aim of this study is to describe hemodynamic characteristics in a cohort of COVID-19-related critically ill patients. Methods. A retrospective observational cohort study in twenty-eight consecutive mechanically ventilated COVID-19 patients. Pulse contour analysis-derived data were obtained from all patients, using the $\mathrm{PiCCO}^{\circledR}$ system. Results. The mean arterial pressure increased from $77 \pm 10 \mathrm{mmHg}$ on day 1 to $84 \pm 9 \mathrm{mmHg}$ on day $21(p=0.04)$, in combination with the rapid tapering and cessation of norepinephrine and the gradual use of antihypertensive drugs in the vast majority of patients. The cardiac index increased significantly from $2.8 \pm 0.7 \mathrm{~L} /$ $\mathrm{min} / \mathrm{m}^{2}$ on day 1 to $4.0 \pm 0.8 \mathrm{~L} / \mathrm{min} / \mathrm{m}^{2}$ on day $21(p<0.001)$. Dobutamine was administered in only two patients. Mean markers of left ventricular contractility and peripheral perfusion, as well as lactate levels, remained within the normal range. Despite a constant fluid balance, extravascular lung water index decreased significantly from $17 \pm 7 \mathrm{~mL} / \mathrm{kg}$ on day 1 to $11 \pm 4 \mathrm{~mL} / \mathrm{kg}$ on day $21(p<0.001)$. Simultaneously, intrapulmonary right-to-left shunt fraction $\left(Q_{s} / Q_{t}\right)$ decreased significantly from $27 \pm 10 \%$ in week 1 to $15 \pm 9 \%$ in week 3 ( $p=0.007) . \mathrm{PaO}_{2} / \mathrm{FiO}_{2}$ ratio improved from $159 \pm 53 \mathrm{mmHg}$ to $319 \pm 53 \mathrm{mmHg}(p<0.001)$, but static lung compliance remained unchanged. Conclusions. In general, this cohort of patients with COVID-19 respiratory failure showed a marked rise in blood pressure over time, not accompanied by distinctive markers of circulatory failure. Characteristically, increased extravascular lung water, vascular permeability, and intrapulmonary shunt diminished over time, concomitant with an improvement in gas exchange.
\end{abstract}

\section{Introduction}

By the spring of 2020, the impact of the COVID-19 pandemic started to materialize. All over the globe, the intensive care unit (ICU) community is faced with overwhelming amounts of patients in need of ICU treatment, predominantly due to acute respiratory failure [1-3]. Efforts are made to understand the rather unique phenotype of a lung disease that fulfills the Berlin criteria for acute respiratory distress syndrome $[4,5]$. It is conceivable that the profound hypoxia in COVID-19 patients is not only a consequence of impaired ventilation, or high incidence of pulmonary embolism, but may also be related to circulatory failure in general [6]. Furthermore, COVID-19 infection is not limited to the lungs but involves other organs as well, including the renal and cardiovascular system $[7,8]$. Several mechanisms related to organ dysfunction beyond the primary target organ have been suggested, including circulatory failure as a result of hyperinflammation, microthrombosis, and heart failure $[9,10]$. However, solid data on cardiovascular derangements in critically ill COVID-19 patients remain scarce. The aim of this study is to describe hemodynamic characteristics in a cohort of COVID-19-related critically ill patients.

\section{Methods}

2.1. Setting and Patient Selection. This retrospective singlecenter study was performed in a closed-format 29-bed mixed ICU in a tertiary teaching hospital. All consecutive patients $\geq 18$ years admitted to the ICU during the period March 15 to 
April 30, 2020, with PCR-confirmed COVID-19 and the need for invasive mechanical ventilation were included in the study. All patients were included in the study within the first 2 hours after intubation. There were no exclusion criteria. The study was performed in accordance with the Declaration of Helsinki, and anonymized data were used for analysis. According to applicable laws, the need for individual consent was waived by a local ethics committee (RTPO nWMO 2020 0027, Regionale Toetsingscommissie Patientgebonden Onderzoek, Leeuwarden, the Netherlands).

2.2. Protocol. A dedicated COVID-19 protocol concerning diagnostics and treatment was designed and approved by the local ICU team before admission of the first COVID-19 patient. In case of respiratory failure, ventilatory support was restricted to invasive mechanical ventilation. Directly after the initiation of mechanical ventilation, a central venous line in the internal jugular vein was inserted, as well as an arterial line in the femoral or brachial artery. Pulse contour analysisderived data were obtained by a $\mathrm{PiCCO}^{\circledR}$ system (Getinge $\mathrm{AB}$, Gothenburg, Sweden). A minimal mean arterial pressure (MAP) was set at $65 \mathrm{mmHg}$, and norepinephrine (NE) was the only available vasopressor. A restrictive policy with respect to fluid administration was maintained throughout the entire ICU admission. In the first week of ICU admission, the preferred ventilatory setting was pressureregulated volume control (PRVC) in combination with midazolam/fentanyl sedation to a Richmond Agitation-Sedation Scale (RASS) level of -4 to -5 and additional muscle paralysis with rocuronium bromide if deemed necessary [11]. Lung-protective mechanical ventilation was applied, using tidal volumes of $6 \mathrm{ml} / \mathrm{kg}$ predicted body weight, positive end-expiratory pressure (PEEP) levels between 8 and $12 \mathrm{~cm} \mathrm{H}_{2} \mathrm{O}$, and driving pressure $<15 \mathrm{~cm} \mathrm{H}_{2} \mathrm{O}$. High fractions of $\mathrm{O}_{2}$ as well as mild hypercapnia (until $\mathrm{pH}$ 7.20-7.25) were accepted. Thrombosis prophylaxis was unaltered during the pandemic and restricted to a normal dose of low molecular weight heparin (nadroparine $0.3 \mathrm{ml}$ subcutaneously, once a day).

2.3. Data Collection. The following data were extracted from the patient data management system (Epic ${ }^{\circledR}$, Verona, Wisconsin, USA): at baseline: demographic characteristics, comorbidities (diabetes, hypertension, and immune-compromised status), and medication (angiotensin-converting enzyme (ACE) inhibitor or angiotensin II receptor blocker). Severity of illness scores (Acute Physiology and Chronic Health Evaluation (APACHE) III and Sequential Organ Failure Assessment (SOFA)) were calculated over the first 24 hours following ICU admission [12, 13]. Furthermore, the maximum SOFA score, need for renal replacement therapy, prone positioning, and number of days in ICU were documented. On a daily basis, fluid balance and body weight were recorded. Delirium was defined as the presence of one or more days with a positive Confusion Assessment Method for the ICU (CAM-ICU) score [14]. Pulmonary embolism was confirmed by CT-scan; aspergillosis was diagnosed by a combination of CT-imaging and a positive galactomannan antigen titer in a bronchoalveolar lavage.

Data were collected for a maximum of 21 consecutive days, or until ICU discharge or death before day 21. Day 21 was chosen since this was the time by which $90 \%$ of all patients were no longer ventilated. The following (semicontinuous) hemodynamic data were extracted once daily at 23.59: MAP, heart rate (HR), central venous pressure (CVP), perfusion index (PI; IntelliVue ${ }^{\circledR}$, Philips Medical Systems, Best, the Netherlands), cardiac index (CI), stroke volume index $\left(\mathrm{SV}_{\mathrm{i}}\right)$, and left ventricular contractility index (dPmax). Global end-diastolic volume index $\left(G \mathrm{GDV}_{\mathrm{i}}\right)$, extravascular lung water index $\left(E L_{L}\right)$, and pulmonary vascular permeability index $\left(\mathrm{PVP}_{\mathrm{i}}\right)$ were recorded during daily calibration of the $\mathrm{PiCCO}^{\circledR}$ system.

Ventilation parameters were recorded once daily simultaneously with hemodynamic data: mode of mechanical ventilation, PEEP settings, fraction of inspired oxygen $\left(\mathrm{FiO}_{2}\right)$, plateau pressure $\left(\mathrm{P}_{\text {plat }}\right)$, static compliance $\left(\mathrm{C}_{\text {stat }}\right)$, and $\mathrm{PaO}_{2} / \mathrm{FiO}_{2}(\mathrm{P} / \mathrm{F})$ ratio. Intrapulmonary right-to-left shunt fractions $\left(Q_{s} / Q_{t}\right)$ were calculated according to Gattinoni et al. and collected once a week [15]. Daily laboratory parameters included blood gas analysis, lactate, creatinine, and sodium. Troponin-T, D-dimer, and procalcitonin were measured twice weekly.

2.4. Statistical Analysis. The data are expressed as mean\pm standard deviation (SD). The Statistical Package for Social Sciences (SPSS 24 for Windows, Chicago, IL, USA) was used for descriptive statistical analysis. Comparison of data was restricted to the difference between day 1 and day 21. Statistical analysis was performed with applicable nonparametric tests for paired data (Wilcoxon), due to the limited number of patients in this study. A $p$ value $<0.05$ was considered statistically significant. Correction for multiple comparisons was not performed.

\section{Results}

3.1. General. During the six-week inclusion period, 30 consecutive patients with polymerase chain reaction-confirmed COVID-19 were admitted to our ICU. Two patients did not need mechanical ventilation and were excluded from further analysis. The mean age was $67 \pm 9$ years, and additional baseline characteristics are summarized in Table 1. Twelve patients (43\%) were admitted after transfer from a primary ICU for logistical reasons, with a mean prior stay of $3 \pm 2$ days. Delirium was the most common complication (95\%).

3.2. Hemodynamic Data. The overall blood pressure was well-preserved. On day 1 , the mean MAP was $77 \pm 10 \mathrm{mmHg} ; 46 \%$ of patients needed vasopressive support with a mean NE dose of $0.04 \pm 0.09 \mu \mathrm{g} / \mathrm{kg} / \mathrm{min}$ (Figure 1). Over time, the MAP increased significantly to $84 \pm 9 \mathrm{mmHg}$ on day $21(p=0.04)$ in combination with a swift and complete weaning from $\mathrm{NE}$ administration in all patients. Simultaneously, a prompt and gradual increase in the administration of (a combination of) antihypertensive drugs 
TABLE 1: Baseline and ICU characteristics.

\begin{tabular}{lc}
\hline Baseline & $n=28$ \\
\hline Age, years & $67 \pm 9$ \\
Male, $n$ (\%) & $20(71)$ \\
BMI, kg/m ${ }^{2}$ & $30 \pm 5$ \\
APACHE III score & $70 \pm 27$ \\
Predicted mortality APACHE IV, \% & $36 \pm 24$ \\
SOFA score (day 1) & $6 \pm 3$ \\
SOFA score (max) & $8 \pm 2$ \\
Comorbidities, $n$ (\%) & \\
Diabetes & $4(14)$ \\
$\quad$ Hypertension & $13(46)$ \\
Immunocompromised & $4(14)$ \\
Medication, $n$ (\%) & \\
$\quad$ ACE inhibitor & $5(18)$ \\
Angiotensin II receptor blocker & $1(4)$ \\
Creatinine ( $\mu$ mol/L) & $93 \pm 66$ \\
\hline ICU period & \\
\hline ICU interventions & \\
$\quad$ Mechanical ventilation, $n$ (\%) & $28(100)$ \\
Mechanical ventilation, days & $17 \pm 4$ \\
Prone positioning, $n(\%)$ & $16(57)$ \\
Muscle relaxants, $n(\%)$ & $26(93)$ \\
Muscle relaxants, days & $11 \pm 5$ \\
Renal replacement therapy, $n(\%)$ & $3(11)$ \\
Complications, $n(\%)$ & $5(18)$ \\
Pulmonary embolism & $3(11)$ \\
Aspergillosis & $27(95)$ \\
Delirium (CAM-ICU confirmed) & $21(75)$ \\
ICU survival, $n(\%)$ & \\
\hline
\end{tabular}

The data are presented as mean \pm SD, unless stated otherwise. BMI: body mass index; APACHE: Acute Physiology and Chronic Health Evaluation; SOFA: Sequential Organ Failure Assessment; ACE: angiotensin-converting enzyme; CAM-ICU: Confusion Assessment Method for the ICU [14].

was observed, including ACE inhibitors, $\beta$-blockers, and calcium antagonists (Figure 1).

The heart rate remained stable over time, from $80 \pm 19$ $\mathrm{bpm}$ on day 1 to $81 \pm 19 \mathrm{bpm}$ on day 21 . In this period, the percentage of patients on $\beta$-blockers increased from $11 \%$ to $80 \%$ (Figure 1).

The cardiac index increased significantly over time, from $2.8 \pm 0.7 \mathrm{~L} / \mathrm{min} / \mathrm{m}^{2}$ on day 1 to $4.0 \pm 0.8 \mathrm{~L} / \mathrm{min} / \mathrm{m}^{2}$ on day 21 $(p<0.001$; Figure 1$)$. In only two patients, dobutamine was administered during less than 48 hours. In addition, CVP decreased gradually from $10 \pm 4 \mathrm{mmHg}$ on day 1 to $6 \pm 3 \mathrm{mmHg}$ on day 20 (Figure 1). CVP is represented in Figure 2. Throughout the study period, serum mean lactate values and the perfusion index remained within the normal range (Figure 2).

Despite a constant $\mathrm{GEDV}_{\mathrm{i}}$ and fluid balance throughout the study period, $E \mathrm{VLW}_{\mathrm{i}}$ decreased significantly from $17 \pm 7 \mathrm{~mL} / \mathrm{kg}$ on day 1 to $11 \pm 4 \mathrm{~mL} / \mathrm{kg}$ on day $21 \mathrm{~mL} / \mathrm{kg}$ $(p<0.001)$, in combination with a significant decrease in $\mathrm{PVP}_{\mathrm{i}}(3.3 \pm 1.1$ and $2.0 \pm 0.6$ respectively, $p<0.001$ ) (Figure 3). Simultaneously, $Q_{s} / Q_{t}$ decreased significantly from $27 \pm 10 \%$ in week 1 to $15 \pm 9 \%$ in week 3 ( $p=0.007$; Figure 3 ).

3.3. Ventilation Data. The mean duration of mechanical ventilation was $17 \pm 4$ days; the mean number of days of muscle relaxants administration was $11 \pm 5$. During mechanical ventilation, $\mathrm{P}_{\text {plat }}$ and $\mathrm{C}_{\text {stat }}$ remained within close range (Figure 4). PEEP was gradually but modestly tapered over time from $10 \pm 2 \mathrm{~cm} \mathrm{H}_{2} \mathrm{O}$ on day 1 to $8 \pm 2 \mathrm{~cm} \mathrm{H}_{2} \mathrm{O}$ on day 21 (Figure 4). In the same period, $\mathrm{P} / \mathrm{F}$ ratio improved significantly from $159 \pm 53 \mathrm{mmHg}$ to $319 \pm 53 \mathrm{mmHg}$, $p<0.001$ (Figure 4). Mean $\mathrm{pH}$ and $\mathrm{CO}_{2}$ remained stable over time (pH $7.38 \pm 0.06$ on day 1 to $7.26 \pm 0.62$ on day 21 , $p=0.07$ and $\mathrm{CO}_{2} 5.8 \pm 1.1 \mathrm{kPa}$ on day 1 to $5.4 \pm 1.7 \mathrm{kPa}$ on day $21, p=0.44$, respectively).

3.4. Additional Data. Additional data are presented in Supplementary Materials. Of note, the steep rise and gradual decline of D-dimer, as well as the increase of Troponin-Tover time, has been depicted (Supplementary Figures 1 and 2).

\section{Discussion}

From these observational data, a consistent picture emerges. In the vast majority of patients, blood pressure is well maintained above $65 \mathrm{mmHg}$ with a very modest dose of $\mathrm{NE}$ in only half of the patients at the start of mechanical ventilation. Over time, there is a striking tendency to hypertension in almost all patients, with a subsequent need for (a combination of) antihypertensive drugs, despite the substantial use of sedatives. In addition, signs of circulatory failure were infrequent. Markers of macrohemodynamic blood flow (CI), left ventricular contractility (dPmax), and preload $\left(G E D V_{i}\right)$ were generally well within the normal range, without substantial administration of fluids or inotropic drug support. In addition, mean values of lactate levels, as a surrogate marker for organ perfusion, and PF index, as an indicator of peripheral perfusion, were not outside reference values. The improvement over time in gas exchange $(\mathrm{P} / \mathrm{F}$ ratio) is accompanied by a marked decrease in markers of permeability-related lung oedema $\left(E L W_{i} /\right.$ $\left.\mathrm{PVP}_{\mathrm{i}}\right)$ and intrapulmonary right-to-left shunt $\left(Q_{s} / Q_{\mathrm{t}}\right)$.

Our data are in line with previous observations of an increased $Q_{s} / Q_{t}$ as a characteristic feature of COVID-19 lung disease, combined with a relatively mild reduction in compliance, as compared with the more classical ARDS $[4,5]$. Data on cardiac output are very scarce, but our observations seem in line with the reported baseline cardiac output in a small intervention study during supine positioning in COVID-19 lung disease [16]. Although clearly elevated, the observed shunt fractions in our study are somewhat lower than previously reported [17]. The characteristic tendency to the development of hypertension is in line with the suggested interference of the coronavirus with the renin-angiotensin-aldosterone system [18]. The welldescribed specific binding of COVID-19 to the ACE-II receptor has been associated with a rise in plasma angiotensin II levels and was linked to the viral load and lung injury [19]. The increase in concentration of an endogenous vasopressor apparently counteracted the histamine-induced vasodilation associated with long-term use of non-depolarizing neuromuscular blockage agents [20]. However, an additional effect of the observed mild hypercarbia cannot be ruled out. 


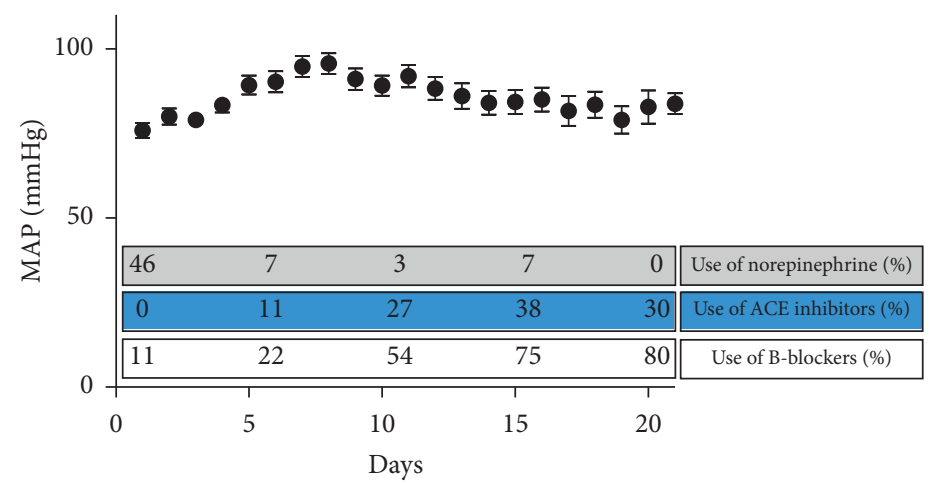

(a)

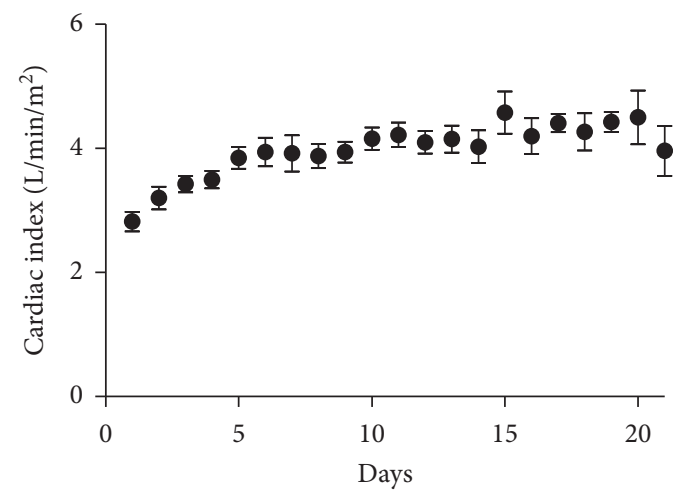

(c)

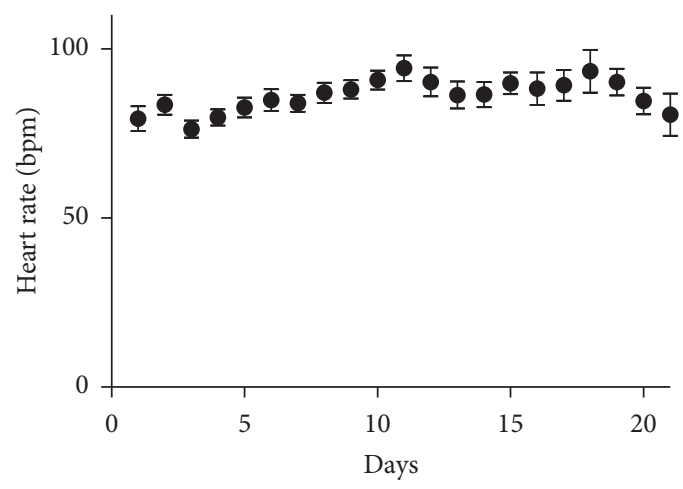

(b)

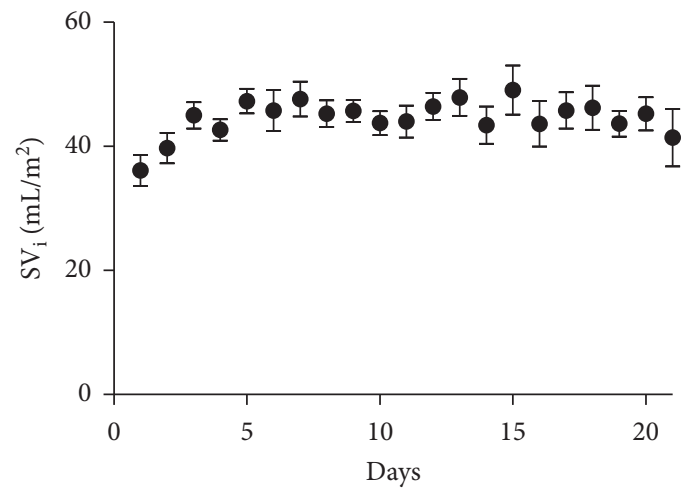

(d)

Figure 1: Circulatory characteristics (I) of COVID-19 patients. MAP: mean arterial pressure; bpm: beats per minute; $\mathrm{SV}_{\mathrm{i}}$ : stroke volume index.

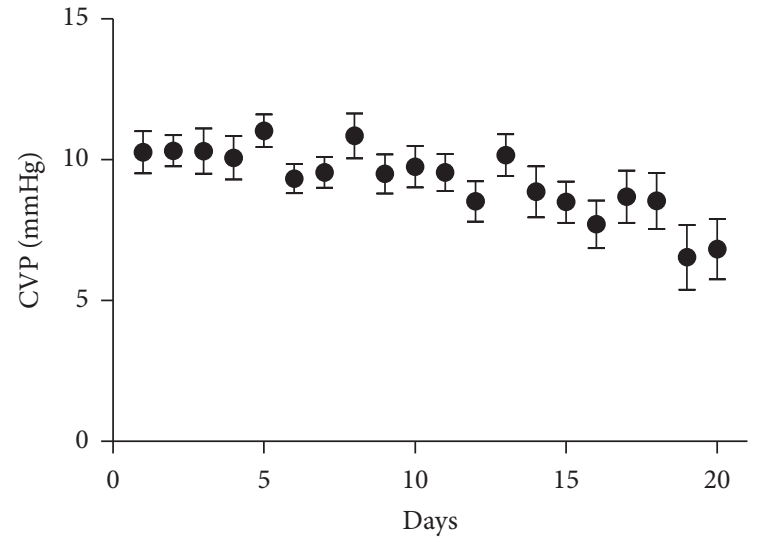

(a)

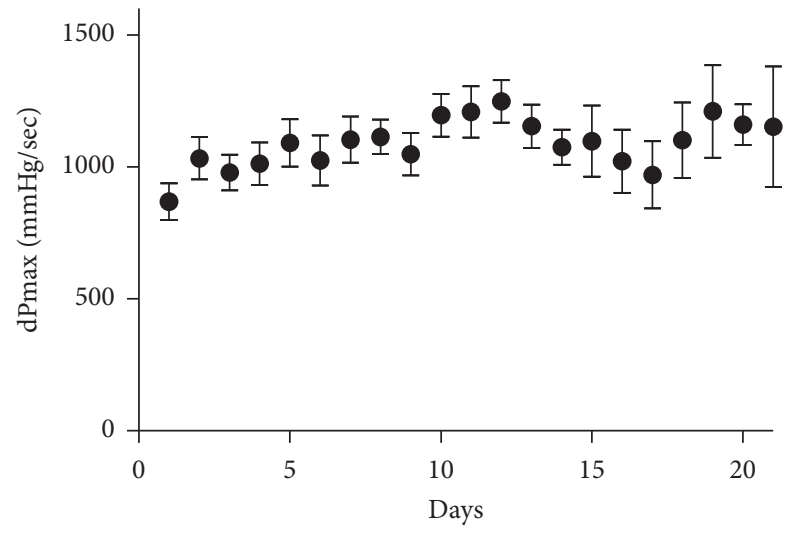

(b)

Figure 2: Continued. 


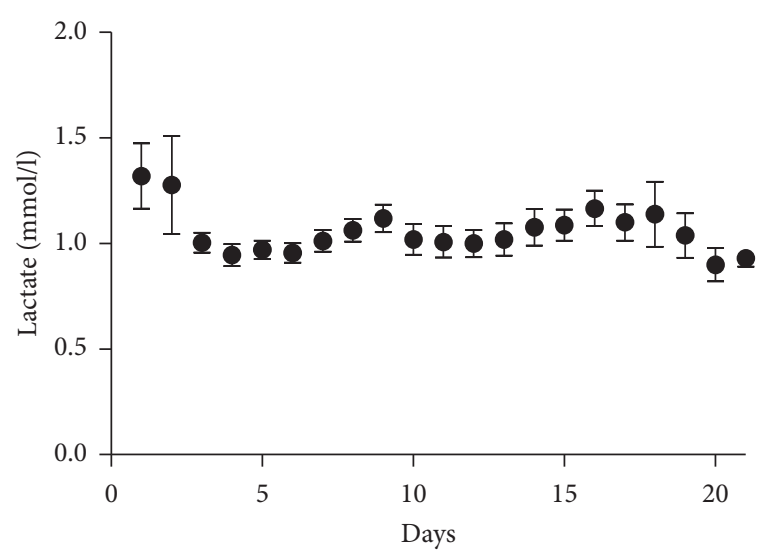

(c)

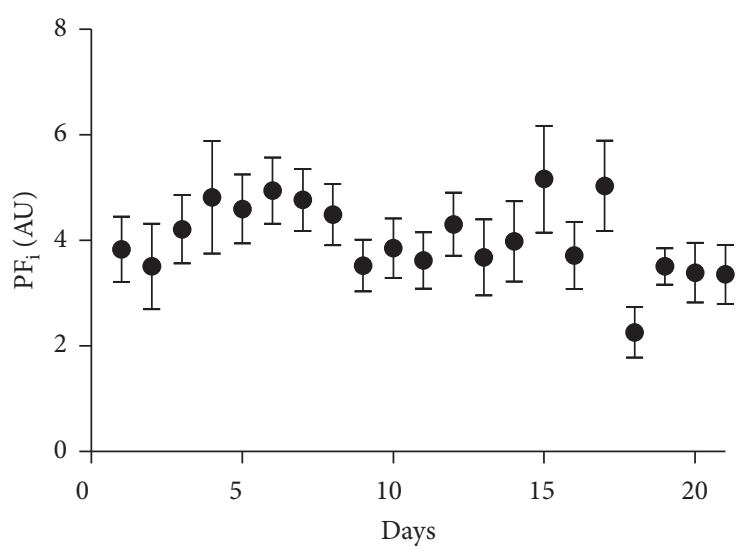

(d)

FIgURE 2: Circulatory characteristics (II) of COVID-19 patients. CVP: central venous pressure; PF $\mathrm{F}_{\mathrm{i}}$ : peripheral perfusion index.

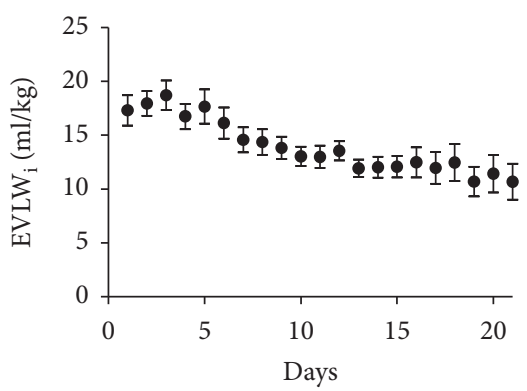

(a)

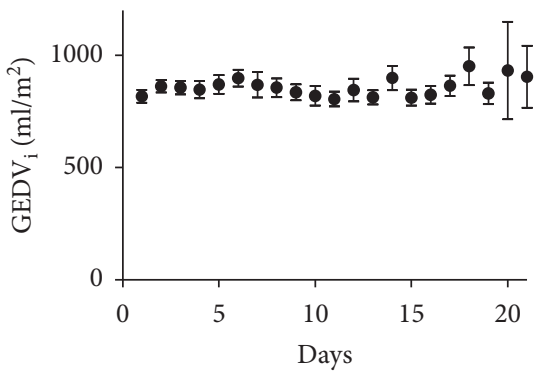

(d)

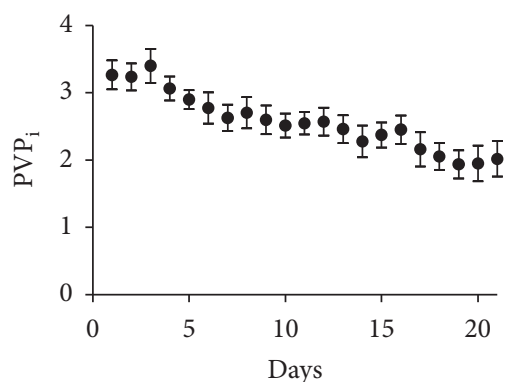

(b)

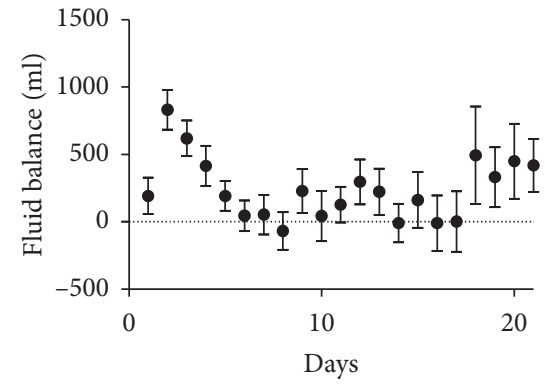

(e)

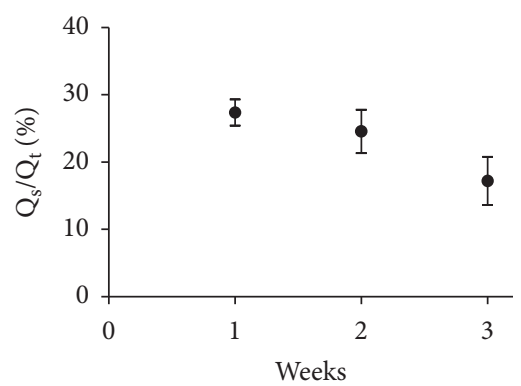

(c)

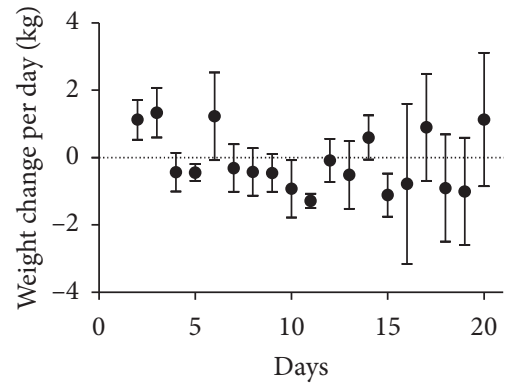

(f)

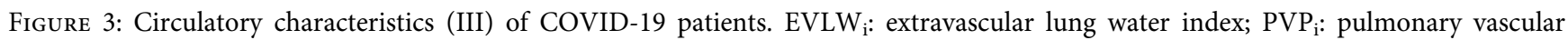
permeability index; $Q_{s} / Q_{t}$ : pulmonary shunt fraction; $\mathrm{GEDV}_{\mathrm{i}}$ : global end-diastolic volume index.

In general, cardiac performance was well-preserved in our patients, despite the observed rise in troponin- $\mathrm{T}$, previously postulated to be a direct marker of myocardial injury in COVID-19 disease $[9,21]$.

Due to the retrospective single-center design of this study, the interpretation of the data does not allow for firm general conclusions, including cause-and-effect relationships. The moderately high severity of illness scores may suggest a form of patient selection, due to local settings. Alternatively, when COVID itself has a moderate impact on systemic hemodynamic variables, this will be reflected by a limited rise in severity of illness scores too. We believe that the specific setting, including a well-protocolized treatment and standardized invasive hemodynamic monitoring in a homogeneous population with confirmed COVID-19 infection and limited comorbidities, offers a unique possibility to increase our knowledge on the hemodynamic features of COVID-19 disease. Due to the descriptive nature of this study, a preset primary endpoint was not formulated. Under these conditions, calculation of statistical differences has limited value but guides the reader to some extent in the interpretation of the graphically presented data. 


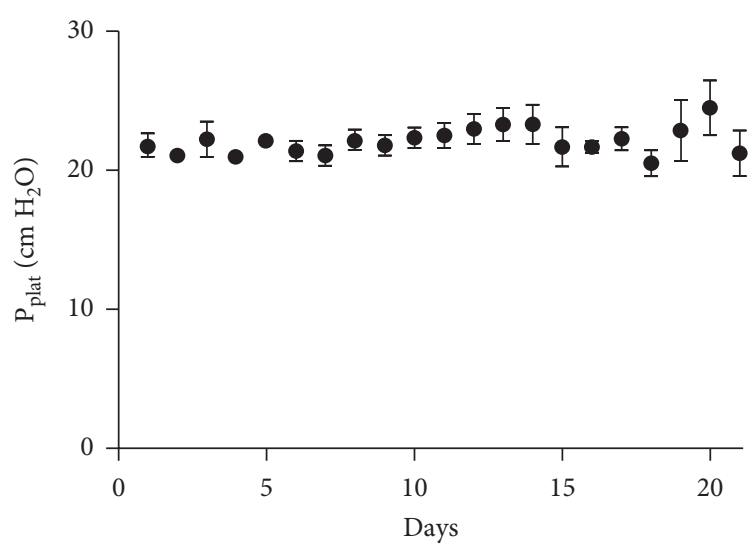

(a)

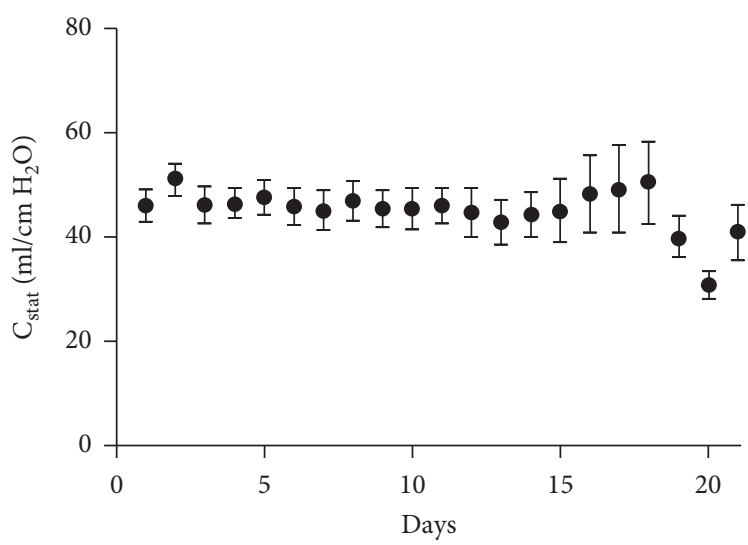

(c)

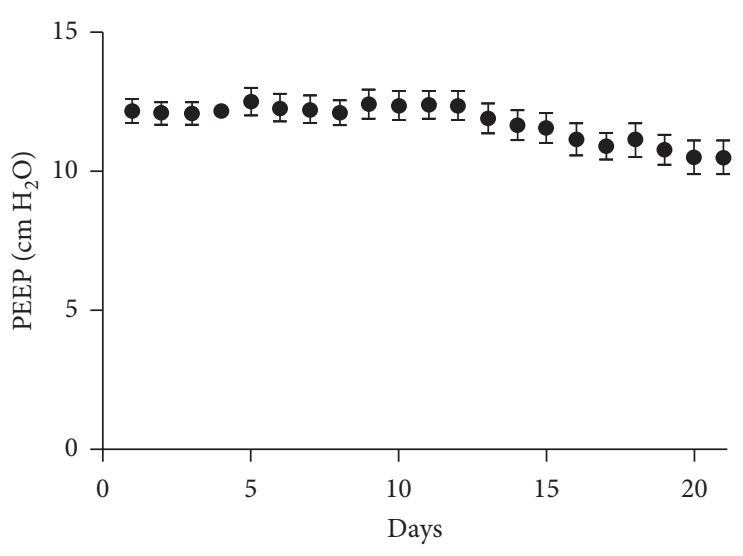

(b)

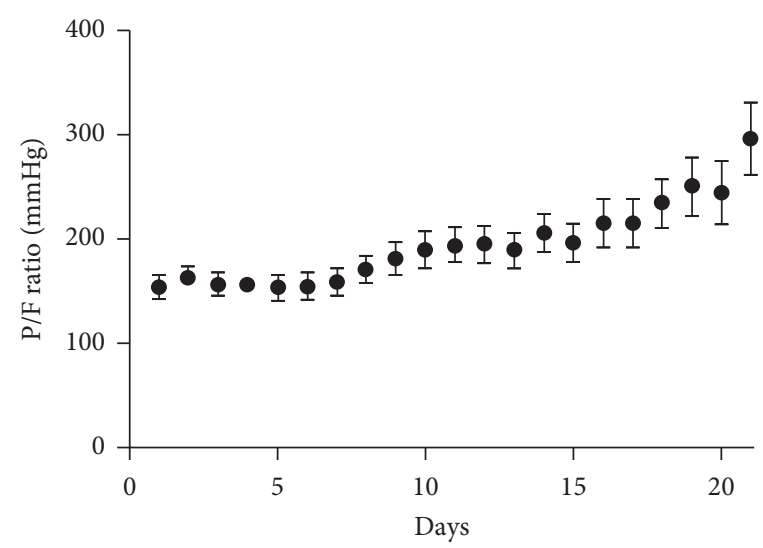

(d)

FIgURE 4: Ventilatory characteristics of COVID-19 patients. $\mathrm{P}_{\text {plat }}$ : plateau pressure; PEEP: positive end-expiratory pressure; $\mathrm{C}_{\text {stat }}:$ static compliance; P/F ratio: $\mathrm{PaO}_{2} / \mathrm{FiO}_{2}$ ratio.

\section{Conclusion}

In conclusion, our observational hemodynamic data in a cohort of mechanically ventilated patients with COVID-19 respiratory failure show a marked rise in blood pressure over time, not accompanied by distinctive markers of circulatory failure. Characteristically, increased extravascular lung water, vascular permeability, and intrapulmonary shunt diminished over time, concomitant with an improvement in gas exchange.

\section{Abbreviations}

ICU: Intensive care unit

MAP: $\quad$ Mean arterial pressure

NE: $\quad$ Norepinephrine

PRVC: Pressure-regulated volume control

RASS: $\quad$ Richmond Agitation-Sedation Scale

PEEP: $\quad$ Positive end-expiratory pressure

ACE: Angiotensin-converting enzyme

APACHE: Acute Physiology and Chronic Health

Evaluation

HR: Heart rate

CVP: Central venous pressure

PI: $\quad$ Perfusion index
CI: $\quad$ Cardiac index

$\mathrm{SV}_{\mathrm{i}}$ : $\quad$ Stroke volume index

dPmax: Left ventricular contractility index

GEDV $_{\mathrm{i}}$ : Global end-diastolic volume index

EVLW $_{\mathrm{i}}$ : $\quad$ Extravascular lung water index

$\mathrm{PVP}_{\mathrm{i}}$ : $\quad$ Pulmonary vascular permeability index

PEEP: $\quad$ Positive end-expiratory pressure

$\mathrm{FiO}_{2}$ : Fraction of inspired oxygen

$\mathrm{P}_{\text {plat }}$ : $\quad$ Plateau pressure

$\mathrm{C}_{\text {stat }}$ : Static compliance

P/F ratio: $\mathrm{PaO}_{2} / \mathrm{FiO}_{2}$ ratio

$\mathrm{Q}_{s} / \mathrm{Q}_{\mathrm{t}}$ : Intrapulmonary right-to-left shunt fractions.

\section{Data Availability}

The datasets used and/or analyzed during the current study are available from the corresponding author on reasonable request. All data generated or analyzed during this study are included in this article and its supplementary information files.

\section{Ethical Approval}

The study was performed in accordance with the Declaration of Helsinki 


\section{Consent}

Due to the observational character of the study and according to applicable laws, a local ethical hospital committee (Regionale Toetsingscommissie Patientgebonden Onderzoek, Leeuwarden, the Netherlands) waived the need for informed consent (RTPO nWMO 2020 0027).

\section{Conflicts of Interest}

The authors declare that they have no conflicts of interest.

\section{Authors' Contributions}

All authors contributed to the study conception and design. Material preparation and data collection were performed by $\mathrm{CB}, \mathrm{KWS}, \mathrm{FS}, \mathrm{PMK}$, and FdL. The statistical analyses were performed by ITB and ECB. The first draft of the manuscript was written by $\mathrm{CB}$ and $\mathrm{ECB}$, and all authors commented on the previous versions of the manuscript. All authors read and approved the final manuscript.

\section{Supplementary Materials}

Figure 1: coagulation and inflammatory parameters. Figure 2: serum sodium and creatinine. (Supplementary Materials)

\section{References}

[1] G. Grasselli, A. Zangrillo, A. Zanella et al., "Baseline characteristics and outcomes of 1591 patients infected with SARSCoV-2 admitted to ICUs of the lombardy region, Italy," Jama, vol. 323, no. 16, pp. 1574-1581, 2020.

[2] S. Richardson, J. S. Hirsch, M. Narasimhan et al., "Presenting characteristics, comorbidities, and outcomes among 5700 patients hospitalized with COVID-19 in the New York city area," JAMA, vol. 323, no. 20, pp. 2052-2059, 2020.

[3] Z. Wu and J. M. McGoogan, "Characteristics of and important lessons from the coronavirus disease 2019 (COVID19) outbreak in China," JAMA, vol. 323, no. 13 , pp. 1239-1242, 2020.

[4] L. Gattinoni, D. Chiumello, P. Caironi et al., "COVID-19 pneumonia: different respiratory treatments for different phenotypes?" Intensive Care Medicine, vol. 46, no. 6, pp. 1099-1102, 2020.

[5] L. Gattinoni, D. Chiumello, and S. Rossi, "COVID-19 pneumonia: ARDS or not?" Critical Care, vol. 24, no. 1, p. 154, 2020.

[6] F. A. Klok, M. J. H. A. Kruip, N. J. M. van der Meer et al., "Incidence of thrombotic complications in critically ill ICU patients with COVID-19," Thrombosis Research, vol. 191, pp. 145-147, 2020.

[7] G. Pei, Z. Zhang, J. Peng et al., "Renal involvement and early prognosis in patients with COVID-19 pneumonia," Journal of the American Society of Nephrology, vol. 31, no. 6, pp. 11571165, 2020.

[8] A. K. Gupta, H. Jneid, D. Addison et al., "Current perspectives on coronavirus disease 2019 and cardiovascular disease: a white paper by the JAHA editors," Journal of the American Heart Association, vol. 9, no. 12, Article ID e017013, 2020.

[9] M. R. Mehra and F. Ruschitzka, "COVID-19 illness and heart failure," JACC: Heart Failure, vol. 8, no. 6, pp. 512-514, 2020.
[10] B. M. Henry, J. Vikse, S. Benoit, E. J. Favaloro, and G. Lippi, "Hyperinflammation and derangement of renin-angiotensinaldosterone system in COVID-19: a novel hypothesis for clinically suspected hypercoagulopathy and microvascular immunothrombosis," Clinica Chimica Acta, vol. 507, pp. 167-173, 2020.

[11] C. N. Sessler, M. S. Gosnell, M. J. Grap et al., "The Richmond agitation-sedation scale," American Journal of Respiratory and Critical Care Medicine, vol. 166, no. 10, pp. 1338-1344, 2002.

[12] J. E. Zimmerman, A. A. Kramer, D. S. McNair, and F. M. Malila, "Acute physiology and chronic health evaluation (Apache) IV: hospital mortality assessment for today's critically ill patients," Critical Care Medicine, vol. 34, no. 5, pp. 1297-1310, 2006.

[13] J.-L. Vincent, A. de Mendonça, F. Cantraine et al., "Use of the SOFA score to assess the incidence of organ dysfunction/ failure in intensive care units," Critical Care Medicine, vol. 26, no. 11, pp. 1793-1800, 1998.

[14] E. W. Ely, R. Margolin, J. Francis et al., "Evaluation of delirium in critically ill patients: validation of the confusion assessment method for the intensive care unit (CAM-ICU)," Critical Care Medicine, vol. 29, no. 7, pp. 1370-1379, 2001.

[15] L. Gattinoni, P. Caironi, M. Cressoni et al., "Lung recruitment in patients with the acute respiratory distress syndrome," New England Journal of Medicine, vol. 354, no. 17, pp. 1775-1786, 2006.

[16] D. S. Karbing, M. Panigada, N. Bottino et al., "Changes in shunt, ventilation/perfusion mismatch, and lung aeration with PEEP in patients with ARDS: a prospective single-arm interventional study," Critical Care, vol. 24, no. 1, p. 111, 2020.

[17] L. Gattinoni, S. Coppola, M. Cressoni, M. Busana, S. Rossi, and D. Chiumello, "COVID-19 does not lead to a typical acute respiratory distress syndrome," American Journal of Respiratory and Critical Care Medicine, vol. 201, no. 10, pp. 1299-1300, 2020.

[18] L. W. Busse, J. H. Chow, M. T. McCurdy, and A. K. Khanna, "COVID-19 and the RAAS-a potential role for angiotensin II?” Critical Care, vol. 24, no. 1, p. 136, 2020.

[19] Y. Liu, Y. Yang, C. Zhang et al., "Clinical and biochemical indexes from 2019-nCoV infected patients linked to viral loads and lung injury," Science China Life Sciences, vol. 63, no. 3, pp. 364-374, 2020.

[20] M. Naguib, A. H. Samarkandi, H. S. Bakhamees, M. A. Magboul, and A. K. el-Bakry, "Histamine-release haemodynamic changes produced by rocuronium, vecuronium, mivacurium, atracurium and tubocurarine," British Journal of Anaesthesia, vol. 75, no. 5, pp. 588-592, 1995.

[21] S. Babapoor-Farrokhran, D. Gill, J. Walker, R. T. Rasekhi, B. Bozorgnia, and A. Amanullah, "Myocardial injury and COVID-19: possible mechanisms," Life Sciences, vol. 253, p. 117723, 2020. 